01.4;03.5;05.3;06.1;14.1

\title{
Особенности влияния исходного состава органических расслаивающихся смесей в микроразмерных порах на взаимную растворимость компонентов
}

\section{(C) А.В. Шишулин, В.Б. Федосеев}

Институт металлоорганической химии им. Г.А. Разуваева РАН, Нижний Новгород, Россия

E-mail: chichouline_alex@live.ru

Поступило в Редакцию 18 мая 2020 г.

В окончательной редакции 18 мая 2020г.

Принято к публикации 23 июня 2020 г.

\begin{abstract}
С помощью методов равновесной химической термодинамики продемонстрировано влияние размера и исходного состава расслаивающихся органических смесей в микроразмерных порах на состав и устойчивость сосуществующих в гетерогенном состоянии фаз. На примере ряда бинарных органических систем показано, что в отличие от макроразмерных фаз в микроразмерных порах взаимная растворимость компонентов существенно зависит от размера поры и исходного состава смеси, при этом характер размерной зависимости растворимостей различен для смесей разного состава. Представлена термодинамическая интерпретация полученных результатов как следствия реализации различных механизмов понижения свободной энергии системы.
\end{abstract}

Ключевые слова: пористые материалы, фазовые превращения, core-shell, расслаивание, растворимость.

DOI: 10.21883/PJTF.2020.18.50005.18383

Интерес к уникальному комплексу свойств многокомпонентных жидких фаз малого объема (свободных или локализованных в порах капель) обусловлен как широким спектром их технологических приложений (комплекс спрей-технологий [1], медицинские технологии $[2,3]$, гибридные функциональные материалы с жидкими растворами в порах твердых матриц [3-6] и др.), так и рядом явлений фундаментального характера [6-10], связанных с особенностями фазовых и химических превращений в микро- и наноразмерных структурах. Подобные особенности проявляются в существенных отличиях термодинамических свойств вещества [11], равновесного состава и устойчивости сосуществующих фаз [7-9,12-15], температур и давлений фазовых переходов [8,9,12-15] в микро- и наноструктурах от соответствующих характеристик макрофаз, а также в специфических динамических эффектах $[10,16]$. Данные отличия зависят от объема, формы капель [7-9] и ряда других факторов. Далее показано, что к числу таких факторов относится химический состав смеси. Если в структурах макроскопического размера вариация состава смеси приводит к изменению объемной доли фаз (описываемому правилом рычага), но не меняет взаимную растворимость компонентов, то в системах малого объема химический состав смеси определяет не только объемную долю фаз, но и их равновесный состав [14,15].

Объектами моделирования являются капли различного состава расслаивающихся растворов олигомерных фракций полибутадиена (PBD) и полистирола (PS), а также воды и фенола, полностью заполняющие сфериче- ские поры различного радиуса. Предполагается, что при расслаивании в порах образуются единичные сферические включения жидкого раствора, окруженные жидким слоем раствора другого состава (core-shell-структура). Равновесный состав сосуществующих фаз определяется минимизацией функции Гиббса с учетом энергетического вклада всех границ раздела (основные уравнения модели расслаивания жидких и твердых растворов в системах ограниченного объема приведены нами в [7-9,14,15]). Функция Гиббса системы PBD-PS по-

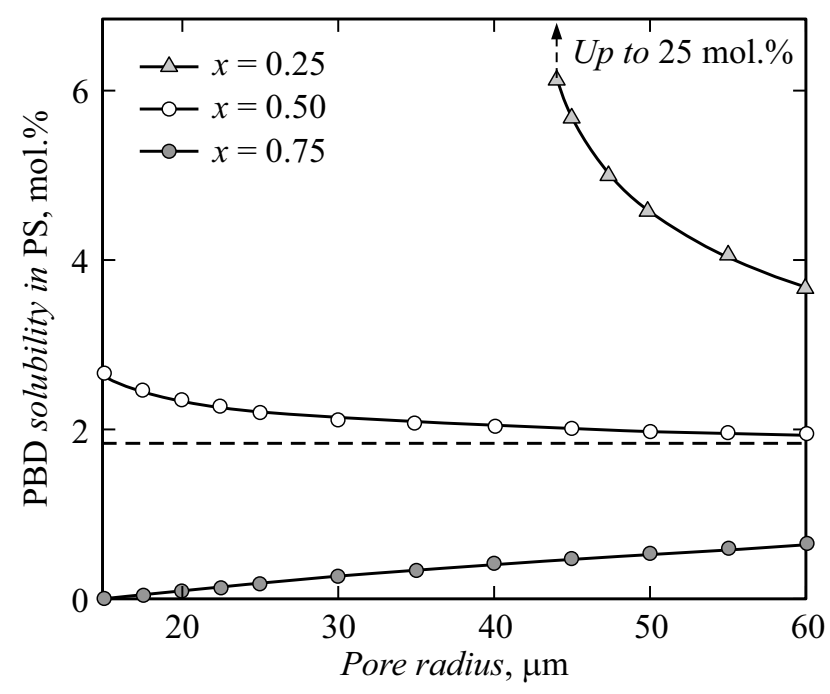

Рис. 1. Зависимость растворимости PBD в PS от радиуса поры и доли PBD $(x)$ в капле. Штриховой линией показана растворимость $\mathrm{PBD}$ в макрофазе. 

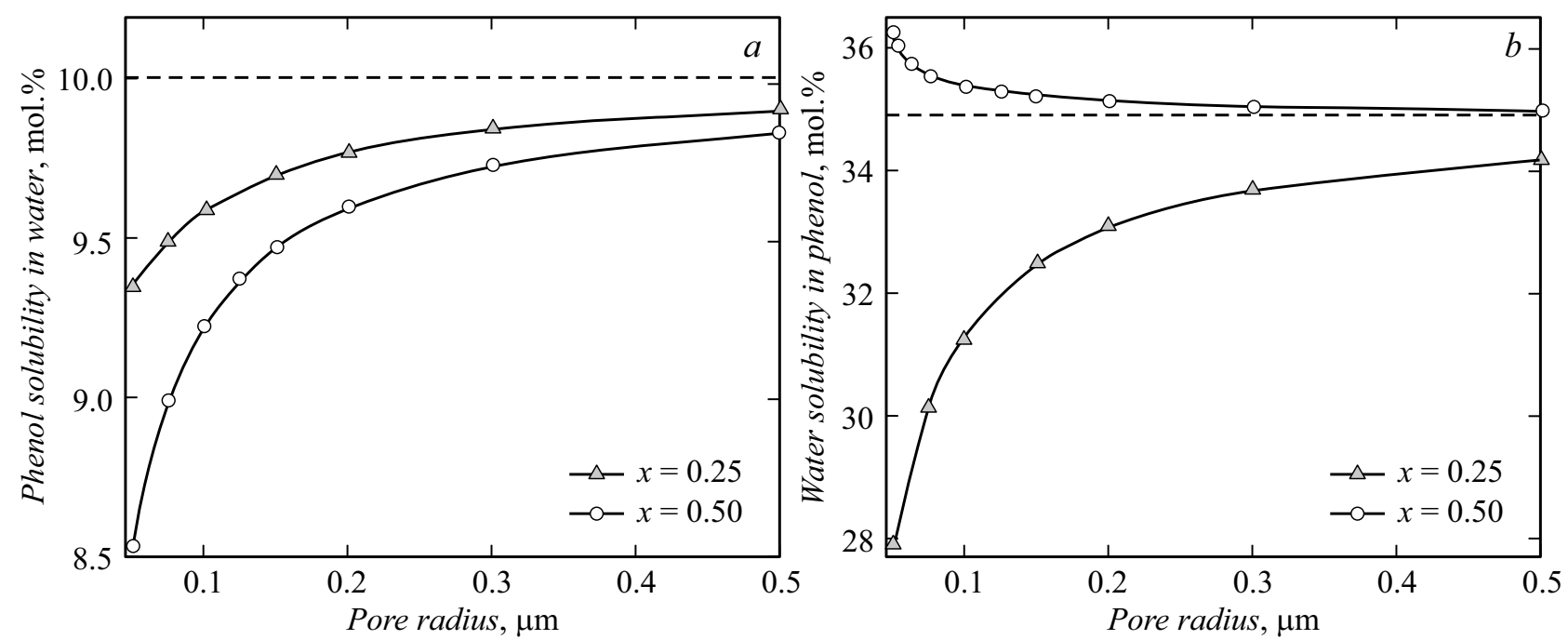

Рис. 2. Зависимости растворимостей фенола в воде $(a)$ и воды в феноле $(b)$ от радиуса поры и доли фенола $(x)$ в капле. Штриховыми линиями показаны соответствующие пределы растворимости в макрофазах. Капля любого радиуса с $x=0.75$ находится в гомогенном состоянии.

строена в рамках модели Флори-Хаггинса, а системы вода-фенол - в рамках модели NRTL (коэффициенты моделей, а также параметры компонентов рассматриваемых систем, включая методы расчета поверхностных натяжений внешней (shell) и внутренней (core-shell) границ приведены в [7,9], где влияние исходного состава системы не рассматривалось).

Как показано в [7-9], функция Гиббса для core-shellструктуры обладает двумя минимумами, различающимися тем, какой из сосуществующих растворов находится в положении shell-фазы. В порах малого объема равновесные составы сосуществующих фаз в этих двух состояниях различаются между собой, отличаются от равновесных составов макрофаз и зависят, например, от объема (и геометрических характеристик) поры. При этом состояния с растворами на основе PBD (в системе PBD-PS) и воды (в системе вода-фенол), имеющие более высокую поверхностную энергию, метастабильны при рассматриваемых температурах и их образование менее вероятно [7,9] (аналогичный эффект также зафиксирован для нанокластеров в рамках ряда иных подходов [17]). Далее рассматриваются случаи, когда shellфазы образованы растворами на основе PS и фенола.

Как показано на рис. 1, для смесей, содержащих 25 mol.\% PBD, растворимость PBD в PS растет с уменьшением радиуса поры $r$, составляя, например, для пор с $r=60$ и $45 \mu \mathrm{m} 3.69$ и $5.65 \mathrm{~mol} . \%$ соответственно. Аналогичная тенденция проявляется для смесей эквимолярного состава, где уменьшение радиуса поры сопровождается ростом растворимости PBD в PS. В каплях смесей, локализованных в порах и содержащих 75 mol.\% PBD, растворимость PBD в PS снижается при уменьшении радиуса поры (от $0.72 \mathrm{~mol} \%$ в поре с $r=60 \mu \mathrm{m}$ до $0.24 \mathrm{~mol} . \%$ при $r=25 \mu \mathrm{m}$ и менее $0.10 \mathrm{~mol} . \%$ при $r=15 \mu \mathrm{m})$. Растворимость PS в PBD в свою очередь снижается при уменьшении размера поры для смесей любого состава (например, с $1.80 \mathrm{~mol} . \%$ при $r=60 \mu \mathrm{m}$ до $1.32 \mathrm{~mol} . \%$ при $r=45 \mu \mathrm{m}$ для смесей с $25 \mathrm{~mol} . \%$ PBD; с $2.36 \mathrm{~mol} \%$ при $r=60 \mu \mathrm{m}$ до $1.16 \mathrm{~mol} \% \%$ при $r=25 \mu \mathrm{m}$ для смесей с $75 \mathrm{~mol} \%$ PBD). В системе вода-фенол (рис. 2) предел растворимости фенола в воде тем меньше, чем меньше радиус капли как в случае капель эквимолярного состава (9.84 mol.\% при $r=0.5 \mu \mathrm{m}, 8.54 \mathrm{~mol} \%$ при $r=0.05 \mu \mathrm{m})$, так и в случае, если капля содержит $25 \mathrm{~mol} \%$ фенола $(9.90 \mathrm{~mol} . \%$ при $r=0.5 \mu \mathrm{m}, 9.35 \mathrm{~mol} . \%$ при $r=0.05 \mu \mathrm{m})$. Растворимость воды в феноле, однако, различается для капель разного исходного состава: возрастает в каплях эквимолярного состава (34.99 mol.\% при $r=0.5 \mu \mathrm{m} 36.29 \mathrm{~mol} . \%$ при $r=0.05 \mu \mathrm{m})$ и снижается в случае $25 \mathrm{~mol} \%$ фенола $(34.17 \mathrm{~mol} \%$ при $r=0.5 \mu \mathrm{m}, 27.88 \mathrm{~mol} \%$ при $r=0.05 \mu \mathrm{m})$. Также отметим, что в системе PBD-PS в каплях, содержащих $25 \mathrm{~mol} \%$ PBD, при $r<44 \mu \mathrm{m}$ минимум функции Гиббса, отвечающий гетерогенному состоянию, исчезает: расслаивание раствора „подавляется“ и капля существует в гомогенном состоянии (показано вертикальной стрелкой на рис. 1).

Полученные закономерности являются следствием понижения системой свободной энергии, что, как показано нами в $[7,8]$, реализуется в core-shell-структуре посредством трех различных механизмов, подробно описанных в [8,9]. Для смеси, содержащей 25 mol.\% PBD, уменьшение объема поры вызывает перенос в shell-фазу компонента с бо́льшим мольным объемом (PBD) [8,9], что приводит к уменьшению площади внутренней межфазной границы. В результате растет растворимость PBD в PS и падает объемная доля core-фазы (с 27.38 vol.\% для поры с $r=60 \mu \mathrm{m}$ до 24.83 vol.\% для поры с $r=24 \mu \mathrm{m}$, при этом энергетический „выигрыш“, связанный с уменьшением энергии границ раздела, превышает „проигрыш“, 
связанный с формированием пересыщенных по сравнению со значениями для макрофаз растворов). Тот же механизм характерен и для смесей эквимолярного состава, в то время как для пор, заполненных смесью c 75 mol.\% PBD, уменьшение радиуса поры сопровождается ростом доли компонента с меньшим поверхностным натяжением (PS) [8,9] в shell-фазе и уменьшением энергетического вклада внешней границы раздела. При этом одновременно происходящее падение содержания PS в core-фазе приводит также и к некоторому снижению ее объемной доли. Подавление расслаивания в порах малого радиуса, заполненных смесью с 25 mol.\% PBD, приводит к понижению энергии системы за счет отсутствия внутренней межфазной границы и соответствует падению верхней критической температуры растворения смеси в поре ниже температуры $T=300 \mathrm{~K}[9,11,12]$. Для смеси вода-фенол с 25 mol.\% фенола уменьшение радиуса поры ведет к падению концентрации воды в shell-фазе (поверхностное натяжение фенола ниже [7]) и уменьшению энергии внешней границы, компенсирующему некоторый рост объемной доли core-фазы (в пределах 2 vol.\%). Для смеси, содержащей 50 mol.\% фенола, при уменьшении объема поры реализуется механизм, связанный со снижением объемной доли coreфазы, компенсирующей в свою очередь некоторый рост концентрации воды в оболочке.

Следует отметить, что аналогичные закономерности получаются при рассмотрении зависимости равновесного фазового состава бинарных смесей от формы капель, задаваемой параметрически (посредством коэффициента формы, характеризующего степень отклонения формы капли от сферической $[8,9]$, или ее фрактальной размерности [7,18], возможен также ряд других подходов $[19,20])$. Как правило, область размеров, в которой реализуются описанные выше эффекты, для растворов олигомерных фракций полимеров выше на несколько порядков, чем для растворов простых органических соединений [7-9], однако и в микроразмерных каплях последних наблюдаются специфические кинетические эффекты при фазовых превращениях („неоствальдовское поведение“ [10]).

\section{Благодарности}

Авторы благодарят всех участников семинара ИМХ РАН, состоявшегося 17 декабря 2019 г., за обсуждение работы и интересную дискуссию.

\section{Финансирование работы}

Работа выполнена в рамках государственного задания ИМХ РАН, а также при поддержке Российского фонда фундаментальных исследований (проекты №№ 18-0801356-а и 18-43-520034-р_поволжье_а).

\section{Конфликт интересов}

Авторы заявляют, что у них нет конфликта интересов.

\section{Список литературы}

[1] Пенязьков О.Г., Саверченко В.И., Фисенко С.П. // Письма в ЖТФ. 2013. Т. 39. В. 3. С. 56-62.

[2] Yakhno T.A., Yakhno V.G., Sanin A.G., Sanina O.A., Pelyushenko A.S., Egorova N.A., Terentiev I.G., Smetanina S.V., Korochkina O.V., Yashukova E.V. // IEEE Eng. Med. Biol. Mag. 2005. V. 24. N 2. P. 96-104.

[3] Acosta C., Pérez-Esteve E., Fuenmayor C.A., Benedetti S., Cosio M.S., Soto J., Sancenón F., Mannino S., Barat J., Marcos M.D., Martínez-Máñez R. // ACS Appl. Mater. Interfaces. 2014. V. 6. N 9. P. 6453-6460.

[4] Брагов А.М., Игумнов Л.А., Константинов А.Ю., Ломунов А.К., Антонов Ф.К., Моссаковский П.А. // Письма в ЖТФ. 2014. Т. 40. В. 20. C. $82-87$.

[5] Li Y., Zhang X., Manyalo J.M., Tian Z., Ji J. // J. Mol. Liq. 2019. V. 277. P. 577-583.

[6] Sato A., Knoll W., Pennec Y., Djafari-Rouhani B., Fytas G., Steinhart M. // J. Chem. Phys. 2009. V. 130. N 11. P. 111102.

[7] Shishulin A.V., Fedoseev V.B. // J. Mol. Liq. 2019. V. 278. P. 363-367.

[8] Шишулин А.В., Федосеев В.Б. // Письма в ЖТФ. 2019. T. 45. B. 14. C. 10-12.

[9] Шишулин А.В., Федосеев В.Б. // ЖТФ. 2020. Т. 90. В. 3. C. 358-364.

[10] Федосеева Е.Н., Федосеев В.Б. // ЖТФ. 2020. Т. 90. В. 6. C. 879-885.

[11] Магомедов М.Н. // ФТТ. 2019. Т. 61. В. 11. С. 2169-2177.

[12] Guisbiers G., Khanal S., Ruiz-Zapeda F., Roque de la Puente J., Yakamán M.J. // Nanoscale. 2014. V. 6. P. 14630-14635.

[13] Bajaj S., Haverty M.G., Arróyave R., Goddard W.A., Shankar S. // Nanoscale. 2015. V. 7. P. 9868-9877.

[14] Шишулин А.В., Федосеев В.Б. // Неорган. материалы. 2019. T. 89. B. 1. C. $16-20$.

[15] Шишулин А.В., Шишулина А.В. // Физико-химические аспекты изучения кластеров, наноструктур, наноматериалов. / Под ред. В.М. Самсонова, Н.Ю. Сдобнякова. Тверь: Твер. гос. ун-т, 2019. С. 268-276.

[16] Яхно Т.А., Яхно В.Г. // ЖТФ. 2017. Т. 87. В. 3. С. 323-330.

[17] Сдобняков Н.Ю., Самсонов В.М., Колосов А.Ю., Васильев С.А., Мясниченко В.С., Соколов Д.Н., Савина К.Г., Веселов А.Д. // Физико-химические аспекты изучения кластеров, наноструктур, наноматериалов. / Под ред. В.М. Самсонова, Н.Ю. Сдобнякова. Тверь: Твер. гос. ун-т, 2019. C. 520-534.

[18] Самсонов В.М., Кузнецова Ю.В., Дьякова Е.В. // ЖТФ. 2016. T. 86. B. 2. C. $71-77$.

[19] Магомедов М.Н. // Письма в ЖТФ. 2016. Т. 42. В. 14. C. $94-102$.

[20] Магомедов М.Н. // Поверхность. Рентгеновские, синхротронные и нейтронные исследования. 2019. № 9. С. $103-$ 112. 